\title{
STRATEGI PEMASARAN PROGRAM STUDI DIPLOMA III USAHA PERJALANAN WISATA UNIVERSITAS JEMBER
}

\author{
Margaretta Andini Nugroho ${ }^{1}$, I Nyoman Darma Putra ${ }^{2}$ \\ ${ }^{1}$ Universitas Jember, ${ }^{2}$ Universitas Udayana \\ Margarettaandininugraha@yahoo.co.id
}

\begin{abstract}
A marketing strategy is needed by Program Studi Diploma III Usaha Perjalanan Wisata (PS D-III UPW) of Jember University, in order to increase more students. Since the last few years, the students of PS D-III UPW has been decreased. This study has the objective to identify strengths, weaknesses, opportunities and threats of PS D-III UPW, and formulate the marketing strategy, by using analysis method of IFAS, EFAS, SWOT and QSPM. The result of IFAS and EFAS identify that PS D-III UPW has 16 factors of strength, 14 factors of weakness, 6 factors of opportunity and 3 factors of threat. The result of SWOT identifies some alternative strategies, which are technology information, student motivation, cooperation within tourism industry, promotion, facilities, competitive product, learning system, quality of human resource, and involvement of the students at Jember tourism events. The QSPM identifies that improvement of promotion as the first priority strategy.
\end{abstract}

Key words: marketing strategy, alternative strategy, priority strategy, Jember University.

\begin{abstract}
Abstrak
Strategi pemasaran dibutuhkan oleh Program Studi Diploma III Usaha Perjalanan Wisata (PS D-III UPW) Universitas Jember, untuk meningkatkan lebih banyak mahasiswa. Sejak beberapa tahun terakhir, siswa PS D-III UPW telah mengalami penurunan. Penelitian ini bertujuan untuk mengidentifikasi kekuatan, kelemahan, peluang dan ancaman PS D-III UPW, dan merumuskan strategi pemasarannya, dengan menggunakan metode analisis IFAS, EFAS, SWOT dan QSPM. Hasil IFAS dan EFAS mengidentifikasi bahwa PS D-III UPW memiliki 16 faktor kekuatan, 14 faktor kelemahan, 6 faktor peluang dan 3 faktor ancaman. Hasil SWOT mengidentifikasi beberapa
\end{abstract}


strategi alternatif, yaitu informasi teknologi, motivasi siswa, kerjasama dalam industri pariwisata, promosi, fasilitas, produk yang kompetitif, sistem pembelajaran, kualitas sumber daya manusia, dan keterlibatan siswa di acara wisata Jember. QSPM mengidentifikasi bahwa peningkatan promosi sebagai strategi prioritas pertama.

Kata kunci: strategi pemasaran, strategi alternatif, strategi prioritas, Universitas Jember

\section{Pendahuluan}

Sumber daya manusia (SDM) yang berkualiatas sangat dibutuhkan pada industri pariwisata. Hal ini dikarenakan pariwisata merupakan industri yang menjual jasa yang kualitas, mutu, harga, reputasi, kelas, dan membutuhkan manusia dalam kinerjanya. Sebagaimana pernyataan dari Evans, Campbell dan Stonehouse (2003) bahwa pariwisata merupakan organisasi berbasis jasa (service-based organization) yang sangat bergantung pada keberadaan SDM, karena terwujudnya pariwisata merupakan interaksi dari manusia yang berperan sebagai konsumen, yaitu pihak-pihak yang melakukan perjalanan wisata (wisatawan) dan manusia sebagai produsen, yaitu pihak-pihak yang menawarkan produk dan jasa wisata, sehingga aspek manusia merupakan salah satu faktor kunci yang berperan penting dalam memajukan sektor pariwisata.

SDM pariwisata yang berkualitas dapat diperoleh salah satunya dari lembaga pendidikan. Irwansyah (2011) mengemukakan bahwa pendidikan kepariwisataan akan mampu memberikan kontribusi yang sangat besar dalam menciptakan SDM pariwisata yang andal dan professional, baik secara kuantitas maupun kualitas dalam mendorong pertumbuhan industri pariwisata secara signifikan.

Salah satu lembaga pendidikan pariwisata di Indonesia yaitu Program Studi Diploma III Usaha Perjalanan Wisata (PS D-III UPW) Universitas Jember. Keberadaan PS D-III UPW ini diharapkan dapat mencetak SDM pariwisata yang berkualitas demi mewujudkan perkembangan pariwisata di Indonesia yang lebih baik lagi, terutama untuk industri biro perjalanan wisata yang saat ini sedang berkembang pesat di Kabupaten Jember. Sayangnya, antusias lulusan Sekolah Menengah Atas untuk melanjutkan pendidikan ke PS D-III UPW masih rendah. Jumlah mahasiswa yang melaksanakan perkuliahan di PS D-III UPW dalam satu dekade terakhir mengalami pasang surut. Pada tahun 2009 jumlah mahasiswanya hanya 9 orang dan hingga tahun 2013 jumlah mahasiswa yang mendaftar masih belum memenuhi target yang ingin dicapai. Berdasarkan pernyataan Ketua PS D-III UPW, Drs. 
Sri Wahyuni, M.Si. pada wawancara hari jumat tanggal 12 Desember 2014 bahwa target yang ingin dicapai PS D-III UPW adalah sejumlah 60 orang mahasiswa. Kondisi ini makin diperparah dengan kurangnya sosialisasi yang dilakukan PS D-III UPW untuk menjaring mahasiswa baru, seperti promosi ke sekolah-sekolah menengah atas ataupun promosi melalui sosial media.

Berdasarkan permasalahan tersebut diperlukan berbagai upaya untuk meningkatkan jumlah mahasiswa dari PS D-III UPW, sehingga dapat meningkatkan jumlah lulusan SDM pariwisata dalam rangka memenuhi tenaga kerja pada industri pariwisata di Jember. Salah satu upaya yang dapat ditempuh adalah melalui strategi pemasaran. Strategi ini akan mengidentifikasi kekuatan, kelemahan, peluang dan ancaman dari PS D-III UPW sehingga bisa dirumuskan strategi alternatif dan strategi prioritas pemasaran yang tepat untuk meningkatkan kuantitas mahasiswa PS D-III UPW.

\section{Teori dan Metode}

Teori yang digunakan dalam artikel ini adalah teori lingkungan pemasaran pendidikan dan teori strategi pemasaran. Menurut Morrison (2002) keberhasilan strategi pemasaran didasarkan atas dua hal, yaitu lingkungan internal pemasaran dan lingkungan eksternal pemasaran. Lingkungan internal pemasaran merupakan bauran pemasaran yang terdiri dari product, price, place, promotion, people, process dan physical evidence, sedangkan lingkungan eksternal pemasaran terdiri dari competition, politic, legislation dan regulation, economic environment, technology, social and cultural dan natural environment. Strategi pemasaran pendidikan menurut Davies dan Ellison (1997) adalah cara yang dilakukan oleh sekolah (lembaga pendidikan) untuk mengkomunikasikan dan mempromosikan tujuan, nilai dan produk sekolah kepada siswa, orang tua dan masyarakat luas.

Metodeyang digunakan dalam artikel ini adalah gabungan antara kualitatif dan kuantitatif. Metode kualitatif digunakan untuk mengidentifikasi faktorfaktor internal dan eksternal lembaga pendidikan. Selanjutnya faktor-faktor internal dan eksternal diproses melalui metode kuantitatif seperti tabulasi perhitungan bobot, rating dan skor. Penerapan metode kualitatif dan kuantitatif menghasilkan strategi alternatif dan strategi prioritas yang tepat bagi PS D-III UPW Universitas jember.

Jenis data pada artikel ini menggabungkan data kualitatif dan kuantitatif. Data kualitatif berupa uraian informasi, seperti gambaran umum tentang lokasi artikel, ide, ungkapan, informasi, kesan, dan saran dari para responden. Data kuantitatif berupa uraian jumlah mahasiswa dan jumlah tenaga pengajar di PS D-III UPW, serta jumlah restoran dan biro perjalanan wisata di Kabupaten jember.

Data yang digunakan dalam artikel ini adalah data primer dan sekunder. 
Data primer diperoleh secara lengsung dari responden yang meliputi tanggapan mahasiswa terhadap faktor-faktor internal pemasaran dan tanggapan dosen terhadap faktor-faktor eksternal pemasaran dari PS D-III UPW di Universitas Jember. Data sekunder diperoleh dari instansi terkait seperti Dinas Pariwisata dan Kebudayaan Kabupaten Jember yang berupa data jumlah restoran dan biro perjalanan wisata.

Instrumen penelitian yang digunakan adalah kuesioner yang diberikan kepada para dosen dan mahasiswa mengenai faktor internal dan eksternal. Kamera handphone untuk merekam gambar dan suara dari objek dan subjek artikel. Selain itu juga menggunakan pedoman wawancara untuk mengetahui latar belakang pendidikan tenaga pengajar, fasilitas kampus, mata kuliah yang diajarkan, dan jumlah mahasiswa di PS D-III UPW.

Populasi dalam artikel ini adalah seluruh mahasiswa yang sedang aktif melaksanakan perkuliahan di PS D-III UPW Universitas Jember yaitu tahun 2012 hingga 2014 yang berjumlah 124 orang mahasiswa, serta seluruh dosen pengajar di PS D-III UPW yang berjumlah 33 orang. Jadi keseluruhan populasi adalah 157 orang. Berdasarkan rumus slovin jumlah sampel yang digunakan adalah 62 orang, sedangkan teknik penarikan sampelnya menggunakan proportionate random sampling yang dapat dilihat pada Tabel 2.1., sehingga diketahui sampel dari mahasiswa angkatan 2012 adalah 13 orang, angkatan 2013 adalah 12 orang, angkatan 2014 adalah 24 orang dan dari lingkungan dosen sejumlah 13 orang.

Tabel 2.1 Metode Penarikan Sampel

\begin{tabular}{clcc}
\hline No. & \multicolumn{1}{c}{ Populasi } & Orang & Jumlah Sampel (orang) \\
\hline 1 & Mahasiswa Angkatan 2012 & 34 & $34 / 158 \times 62=13$ \\
2 & Mahasiswa Angkatan 2013 & 30 & $30 / 158 \times 62=12$ \\
3 & Mahasiswa Angkatan 2014 & 60 & $60 / 158 \times 62=24$ \\
4 & Dosen Pengajar & 34 & $34 / 158 \times 62=13$ \\
Jumlah & & 158 & 62 \\
\hline
\end{tabular}

Sumber: Data Diolah, 2015.

Variabel penelitian terdiri dari variabel internal dan eksternal yang masing-masing disertai indikatornya, seperti pada Tabel 2.1 dan Tabel 2.2.

Teknik pengumpulan data melalui observasi, wawancara, angket dan dokumentasi. Observasi dilakukan dengan cara mengumpulkan data berdasarkan pengamatan secara langsung terhadap di lokasi PS D-III UPW. Wawancara mendalam dilakukan terhadap dekan, ketua program studi, dosen, beserta staf akademik. Angket disebarkan dalam bentuk kuesioner kepada mahasiswa dan dosen. Dokumentasi merupakan pengumpulan data berbagai dokumen dari PS D-III UPW dan Dinas Kebudayaan dan Pariwisata Kabupaten Jember. 
Tabel 2.1 Variabel dan Indikator Faktor-faktor Eksternal

\begin{tabular}{|c|c|c|}
\hline No & Variabel & Indikator \\
\hline & Competition & $\begin{array}{l}\text { a. Persaingan antara Universitas Jember dengan } \\
\text { universitas lain yang membuka jurusan pariwisata } \\
\text { di Kabupaten jember }\end{array}$ \\
\hline & $\begin{array}{l}\text { Politic, Legislation, dan } \\
\text { Regulation }\end{array}$ & $\begin{array}{l}\text { a. Peranan Pemerintah Kabupaten Jember pada } \\
\text { pembangunan pariwisata di Jember } \\
\text { b. Kebijakan pemerintah Kabupaten Jember tentang } \\
\text { agenda pariwisata }\end{array}$ \\
\hline & Economic Environment & $\begin{array}{l}\text { a. Perkembangan industri pariwisata di Jember } \\
\text { b. Kerjasama dalam pemberian beasiswa }\end{array}$ \\
\hline & Technology & $\begin{array}{l}\text { a. Globalisasi informasi dalam menjangkau calon } \\
\text { mahasiswa } \\
\text { b. Teknologi informasi dalam operasional perkuliahan }\end{array}$ \\
\hline & Societal dan cultural & $\begin{array}{l}\text { a. Minat pelajar Kabupaten Jember terhadap } \\
\text { pariwisata }\end{array}$ \\
\hline & Natural Environment & $\begin{array}{l}\text { a. Potensi sumber daya alam Kabupaten Jember dalam } \\
\text { mengembangkan pariwisata }\end{array}$ \\
\hline
\end{tabular}

Tabel 2.2 Variabel dan Indikator Faktor-faktor Internal

\begin{tabular}{|c|c|c|}
\hline No. & Variabel & Indikator \\
\hline 1 & Product & $\begin{array}{l}\text { a. Kesesuaian mata kuliah } \\
\text { b. Beasiswa } \\
\text { c. Akreditasi lembaga pendidikan } \\
\text { d. Kerjasama PS D-III UPW dengan berbagai instansi } \\
\text { e. Keberadaan ekstra kurikuler }\end{array}$ \\
\hline 2 & Price & $\begin{array}{l}\text { a. Biaya pendaftaran masuk universitas } \\
\text { b. Biaya SPP } \\
\text { c. Sistem pembayaran biaya pendidikan } \\
\text { d. Kesesuaian biaya kuliah dengan fasilitas yang diterima }\end{array}$ \\
\hline 3 & Place & $\begin{array}{l}\text { a. Lokasi kampus strategis } \\
\text { b. Lokasi kampus yang aman dan nyaman }\end{array}$ \\
\hline 4 & Promotion & $\begin{array}{l}\text { a. Promosi melalui media cetak } \\
\text { b. Promosi melalui internet } \\
\text { c. Promosi oleh alumi } \\
\text { d. Promosi melalui sosialisasi langsung ke SMA/SMK } \\
\text { e. Promosi melalui pameran pendidikan }\end{array}$ \\
\hline 5 & People & $\begin{array}{l}\text { a. Kualifikasi pendidikan dosen } \\
\text { b. Kemampuan cara belajar mengajar dosen } \\
\text { c. Kemampuan dosen member motivasi pada mahasiswa } \\
\text { d. Pelayanan tenaga administrasi } \\
\text { e. Kinerja staf keamanan }\end{array}$ \\
\hline 6 & Process & $\begin{array}{l}\text { a. Prosedur registrasi dan penerimaan mahasiswa } \\
\text { b. Keseimbangan antara teori dan praktek diperkuliahan } \\
\text { c. Kemudahan melakukan keluhan akademik } \\
\text { d. Kerjasama dengan alumni PS D-III UPW }\end{array}$ \\
\hline 7 & $\begin{array}{l}\text { Physical Evi- } \\
\text { dence }\end{array}$ & $\begin{array}{l}\text { a. Tampilan bangunan atau gedung lembaga pendidikan } \\
\text { b. Kebersihan dan kenyamanan ruang kelas } \\
\text { c. Tersedianya sarana perkuliahan } \\
\text { d. Tersedianya prasarana penunjang perkuliahan } \\
\text { e. Tersedianya prasarana pendukung perkuliahan }\end{array}$ \\
\hline
\end{tabular}




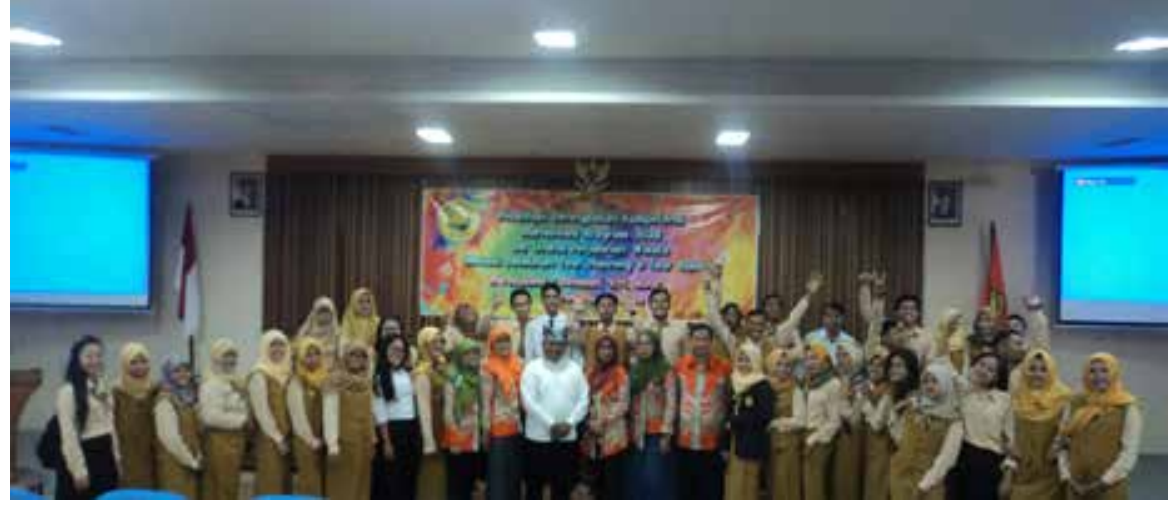

Foto 1. Mahasiswa berfoto bersama sebelum melakukan pelatihan perencaan tur dan pemandu wisata.

Matrik internal factor analisys summary (IFAS) dan matrik eksternal factor analisys summary (EFAS) digunakan untuk mengetahui kekuatan, kelemahan, peluang dan ancaman, selanjutnya analisis SWOT (Strength, Weaknesses, Opportunites, Threat) untuk menghasilkan strategi alternatif dan analisis QSPM (Quantitative Strategics Planning Matrix) untuk menghasilkan strategi prioritas.

\section{Hasil dan Pembahasan}

\subsection{Kekuatan, Kelemahan, Peluang dan Ancaman dari PS D-III UPW}

Kekuatan dan kelemahan diperoleh berdasarkan penilaian mahasiswa terhadap indikator internal pemasaran, sedangkan peluang dan ancaman berdasarkan penilaian dosen terhadap indikator eksternal pemasaran.

Kekuatan dari PS D-III UPW adalah pemberian beasiswa, akreditasi lembaga pendidikan, keberadaan ekstra kurikuler, biaya kuliah, lokasi kampus, sistem registrasi, pelayanan akademik, jenjang pendidikan dosen, kinerja staf keamanan, tampilan bangunan, prasarana penunjang, kebersihan dan kenyamanan ruang kelas.

Kelemahan dari PS D-III UPW yaitu kesesuaian mata kuliah, kerja sama dengan berbagai perusahaan, kesesuaian biaya kuliah dengan fasilitas yang diterima, promosi melalui media cetak, promosi melalui internet, promosi oleh alumni, promosi melalui sosialisasi ke SMA, promosi melalui pameran pendidikan, kemampuan mengajar dosen, kemampuan dosen memberikan motivasi belajar mahasiswa, kerjasama dengan alumni PS D3UPW, kesesuaian antara teori \& praktek, keberadaan sarana perkuliahan dan keberadaan prasarana pendukung perkuliahan.

Peluang dari PS D-III UPW yaitu perkembangan industri pariwisata di Jember, kerjasama dengan berbagai instansi dalam pemberian beasiswa, globalisasi informasi dalam menjangkau calon mahasiswa yang lebih luas, teknologi informasi dalam operasonal perkuliahan, daya minat pelajar Kabupaten Jember bekerja di bidang pariwisata, dan sumber daya alam Kabupaten Jember sebagai potensi Pariwisata Jember. 
Ancaman dari PS D-III UPW yaitu intensitas daya saing Universitas Jember dengan universitas-universitas di Kabupaten Jember yang memiliki jurusan bidang pariwisata (Politeknik Jember dan Universitas Muhammadiyah Jember) dalam mendapatkan calon mahasiswa, peranan Pemerintah Kabupaten Jember pada pembangunan pariwisata di Jember, dan kebijakan Pemerintah Kabupaten Jember tentang agenda pariwisata.

\subsection{Strategi Alternatif Pemasaran PS D-III UPW}

Strategialternatif pemasaran PS D-III UPW diformulasikan menggunakan analisis matriks EFAS (Tabel 3.1), matriks IFAS (Tabel 3.2) dan SWOT (Tabel 3.3). Dari Tabel 3.1 dapat diketahui bahwa posisi lingkungan eksternal PS D-III UPW Universitas Jember secara umum memiliki peluang yang sangat kuat. Hal ini bisa dilihat dari selisih total nilai skor peluang yang sangat tinggi. Total skor dari peluang adalah 2.027 sedangkan total skor dari ancaman adalah 0.715 , sehingga selisih total skor antara peluang dan ancaman sangat tinggi yaitu sebesar 1.312 .

Dari Tabel 3.2 dapat diketahui bahwa posisi lingkungan internalnya secara umum pada posisi cukup baik. Hal ini bisa dilihat dari total skor kekuatan adalah 1.541 sedangkan total skor dari kelemahan adalah 1.117, sehingga selisih total skor antara kekuatan dan kelemahan tidak begitu besar yaitu hanya 0,424 .

Tabel 3.1 Matriks EFAS

\begin{tabular}{|c|c|c|c|c|}
\hline \multicolumn{2}{|r|}{ No Faktor-Faktor Eksternal Pemasaran PS D-III UPW } & \multirow[t]{2}{*}{$\begin{array}{c}\text { Bobot } \\
\text { (B) }\end{array}$} & \multirow[t]{2}{*}{$\begin{array}{l}\text { Rating } \\
(\mathrm{R})\end{array}$} & \multirow[t]{2}{*}{$\begin{array}{c}\text { Skor } \\
(\mathrm{BxR})\end{array}$} \\
\hline A & PELUANG (Opportunities) & & & \\
\hline 1 & Perkembangan industri pariwisata di Jember & 0.101 & 3.46 & 0.349 \\
\hline 2 & $\begin{array}{l}\text { Kerjasama dengan berbagai instansi dalam pemberian } \\
\text { beasiswa }\end{array}$ & 0.121 & 3.54 & 0.428 \\
\hline 3 & $\begin{array}{l}\text { Globalisasi informasi dalam menjangkau calon maha- } \\
\text { siswa yang lebih luas }\end{array}$ & 0.119 & 3.23 & 0.384 \\
\hline 4 & Teknologi informasi dalam operasional perkuliahan & 0,116 & 3.46 & 0,401 \\
\hline 5 & $\begin{array}{l}\text { Daya minat pelajar Kabupaten Jember bekerja di } \\
\text { bidang pariwisata }\end{array}$ & 0.112 & 3.54 & 0.396 \\
\hline 6 & $\begin{array}{l}\text { Sumber daya alam Kabupaten Jember dalam mengem- } \\
\text { bangkan pariwisata Jember }\end{array}$ & 0.120 & 3.92 & 0.470 \\
\hline & TOTAL SKOR & & & 2.027 \\
\hline B & ANCAMAN (Threats) & & & \\
\hline 1 & $\begin{array}{l}\text { Intensitas daya saing Universitas Jember dengan uni- } \\
\text { versitas-universitas di Kabupaten Jember yang memi- } \\
\text { liki jurusan bidang pariwisata (Politeknik Jember dan } \\
\text { Universitas Muhammadiyah Jember) dalam mendapa- }\end{array}$ & 0.086 & 2,38 & 0.205 \\
\hline
\end{tabular}


2 Peranan Pemerintah Kabupaten Jember pada pemban- $0.109 \quad 2.15 \quad 0.234$ gunan pariwisata di Jember

3 Kebijakan Pemerintah Kabupaten Jember tentang $\quad \begin{array}{lll}0.116 & 2.38 & 0.276\end{array}$ agenda pariwisata

\begin{tabular}{lll} 
TOTAL SKOR & 1.000 & 0.715 \\
\hline
\end{tabular}

Sumber: Data Diolah, 2015

Tabel 3.2 Matriks IFAS

\begin{tabular}{|c|c|c|c|c|}
\hline No & Faktor-Faktor Internal Pemasaran PS D-III UPW & $\begin{array}{l}\text { Bobot } \\
\text { (B) }\end{array}$ & $\begin{array}{l}\text { Rating } \\
(\mathrm{R})\end{array}$ & $\begin{array}{c}\text { Skor } \\
\text { (BxR) }\end{array}$ \\
\hline \multicolumn{5}{|c|}{ A KEKUATAN (Strengths) } \\
\hline 1 & Pemberian Beasiswa & 0.033 & 2.63 & 0.087 \\
\hline 2 & Akreditasi lembaga pendidikan & 0.034 & 3.14 & 0.107 \\
\hline 3 & $\begin{array}{l}\text { Kegiatan kemahasiswaan non akademik / ekstra } \\
\text { kurikuler sebagai sarana pengembangan minat dan } \\
\text { bakat mahasiswa }\end{array}$ & 0.032 & 3.02 & 0.097 \\
\hline 4 & Biaya pendaftaran masuk universitas & 0.031 & 2.76 & 0.086 \\
\hline 5 & Biaya SPP & 0.031 & 2.63 & 0.082 \\
\hline 6 & Sistem pembayaran & 0.031 & 2.82 & 0.087 \\
\hline 7 & Lokasi kampus strategis & 0.034 & $3 \cdot 37$ & 0.115 \\
\hline 8 & Lokasi kampus aman dan nyaman & 0.034 & $3 \cdot 35$ & 0.114 \\
\hline 9 & Prosedur registrasi dan penerimaan mahasiswa & 0.033 & 2.92 & 0.096 \\
\hline 10 & Kemudahan melakukan keluhan akademik & 0.033 & 2.82 & 0.093 \\
\hline 11 & Kualifikasi pendidikan dosen & 0.033 & 3.10 & 0.102 \\
\hline 12 & Pelayanan tenaga administrasi & 0.034 & 2.90 & 0.097 \\
\hline 13 & Kinerja Staff Keamanan & 0.034 & 3.00 & 0.102 \\
\hline 14 & $\begin{array}{l}\text { Tampilan bangunan atau gedung lembaga pendi- } \\
\text { dikan }\end{array}$ & 0.034 & 2.76 & 0.094 \\
\hline 15 & $\begin{array}{l}\text { Keberadaan prasarana penunjang perkuliahan } \\
\text { (Perpustakaan dengan kelengkapan buku, laborato- } \\
\text { rium, dan fasilitas olah raga) }\end{array}$ & 0.034 & 2.63 & 0.089 \\
\hline \multirow[t]{2}{*}{16} & Kebersihan dan kenyamanan ruang kelas & 0.034 & 2.73 & 0.093 \\
\hline & & & & 1.541 \\
\hline B & KELEMAHAN (Weaknesses) & & & \\
\hline 1 & $\begin{array}{l}\text { Kesesuaian mata kuliah dengan kebutuhan pasar } \\
\text { tenaga kerja }\end{array}$ & 0.034 & 2.43 & 0.083 \\
\hline 2 & $\begin{array}{l}\text { Kerjasama dengan berbagai perusahaan untuk } \\
\text { program magang sebagai media memperkenalkan } \\
\text { mahasiswa pada dunia kerja }\end{array}$ & 0.035 & 2.31 & 0.081 \\
\hline 3 & $\begin{array}{l}\text { Kesesuaian biaya kuliah dengan fasilitas yang } \\
\text { diterima }\end{array}$ & 0.034 & 2.31 & 0.079 \\
\hline 4 & $\begin{array}{l}\text { Promosi D-III UPW melalui radio, surat kabar, } \\
\text { brosur, spanduk, dan papan reklame }\end{array}$ & 0.034 & 2.41 & 0.082 \\
\hline 5 & Promosi D-III UPW melalui internet & 0.034 & 2.27 & 0.077 \\
\hline 6 & Promosi D-III UPW oleh alumni & 0.033 & 2.02 & 0.067 \\
\hline 7 & $\begin{array}{l}\text { Promosi D-III UPW melalui sosialisasi ke SMA / } \\
\text { SMK }\end{array}$ & 0.034 & 2.10 & 0.071 \\
\hline 8 & Promosi D-III UPW melalui pameran pendidikan & 0.030 & 2.35 & 0.071 \\
\hline 9 & Kemampuan mengajar dosen & 0.034 & 2.98 & 0.101 \\
\hline
\end{tabular}


10 Kemampuan dosen memberikan motivasi belajar mahasiswa

$0.034 \quad 2.43 \quad 0.083$

11 Kerjasama dengan alumni PS D-III UPW

$0.034 \quad 2.43 \quad 0.083$

12 Kesesuaian antara teori dan praktek

$0.033 \quad 2.41 \quad 0.080$

13 Keberadaan sarana perkuliahan

$0.034 \quad 2.24 \quad 0.076$

15 Keberadaan prasarana pendukung perkuliahan

$0.034 \quad 2.43 \quad 0.083$
TOTAL SKOR 1.000 1.117

Sumber : Data Diolah, 2015

Berdasarkan hasil yang didapat dari matriks eksternal-internal tersebut maka dihasilkan matriks posisi dari PS D-III UPW Universitas Jember, seperti pada Gambar 3.1.

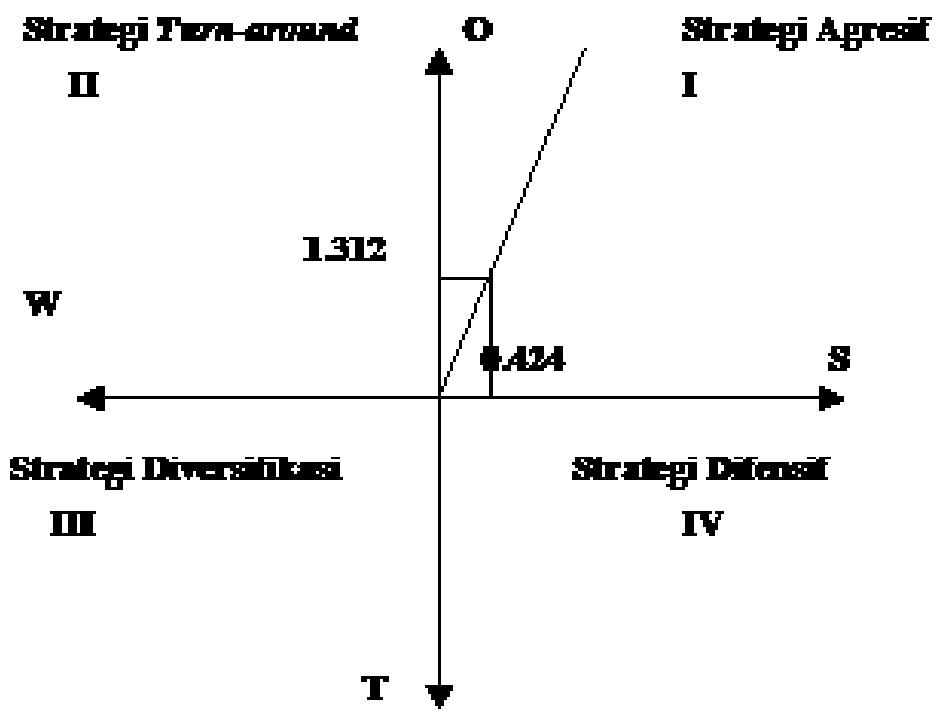

Gambar 3.1 Matriks Posisi PS D-III UPW Universitas Jember

Berdasarkan matriks posisi, PS DIII UPW Universitas Jember berada pada kuadran 1, oleh karena itu strategi yang harus diterapkan adalah Tumbuh dan Kembangkan, yang terdiri atas strategi penetrasi pasar, pengembangan pasar, dan strategi pengembangan produk.

Berdasarkan data dan informasi pada Tabel 3.1 dan Tabel 3.2 maka dihasilkan matriks SWOT seperti pada Tabel 3.3 dengan sembilan strategi alternatif yang mencakup strategi Strengths Opportunities (S-O), strategi Weaknesses-Opportunities (W-O), strategi Strengths-Threats (S-T) dan strategi Weaknesses-Threats (W-T).

a. Strategi SO (Strengths-Opportunities)

Strategi alternatif SO yaitu peningkatan teknologi informasi dan peningkatan daya minat pelajar menengah atas terhadap PS D-III UPW 


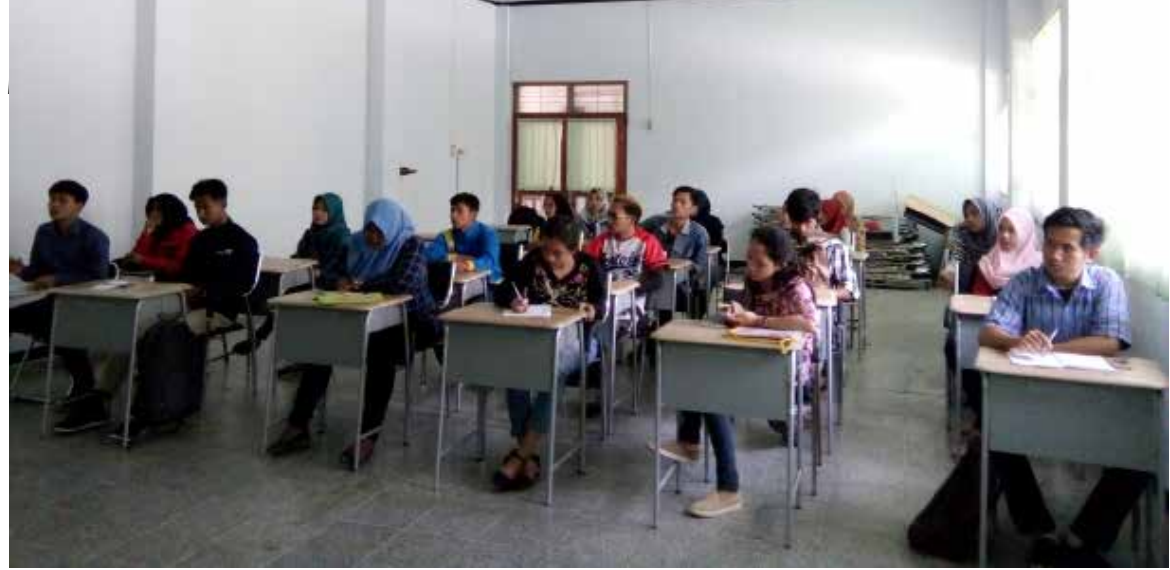

Foto 2. Mahasiswa mengikuti perkualiahan.

b. Strategi WO (Weaknesses - Opportunities)

Strategi alternatif WO yaitu peningkatan kerjasama antara PS D-III UPW dan stakeholders, peningkatan promosi dan peningkatan sarana prasarana.

c. Strategi ST (Strengths - Threats)

Strategi alternatif ST yaitu peningkatan keunggulan PS D-III UPW seperti memperbanyak ekstra kurikuler dan penambahan pemberian beasiswa.

d. Strategi WT (Weaknesses - Threats)

Strategi alternatif WT yaitu pembenahan mata kuliah, peningkatan kualitas sumber daya manusia, mengikutsertakan mahasiswa PS D-III UPW diberbagai event pariwisata yang diselenggarakan pemerintah.

\subsection{Strategi Prioritas Pemasaran PS D-III UPW}

Prioritas strategi adalah menentukan strategi yang dianggap paling baik untuk segera diimplementasikan pada PS D-III UPW Universitas Jember. Prioritas strategi dihasilkan melalui analisis matriks QSPM. Matriks QSPM dihasilkan melalui pemaduan antara faktor-faktor internal dan eksternal, kemudian diidentifikasi strategi alternatif mana yang memiliki nilai yang paling tinggi. Berdasarkan hasil analisis QSPM pada Tabel 3.4, yang menunjukkan prioritas strategi yang memiliki peringkat paling tinggi sebesar 21.582 adalah peningkatan promosi PS D-III UPW Universitas Jember.

Dapat disimpulkan bahwa sembilan strategi yang bisa diterapkan di PS D-III UPW dengan skala prioritas adalah sebagai berikut :

1. Peningkatan promosi PS D-III UPW melalui berbagai media (21.582)

2. Peningkatan daya minat pelajar terhadap PS D-III UPW (20.770)

3. Peningkatan kerjasama PS D-III UPW dengan berbagai lembaga (20.334)

4. Peningkatan kualitas sumber daya manusia PS D-III UPW (19.833)

5. Peningkatan keunggulan PS D-III UPW(19.364)

6. Menciptakan kerjasama antara PS D-III UPW dengan pemerintah 
Tabel 3.3 Analisis SWOT Pemasaran PS D-III UPW Universitas Jember

\begin{tabular}{|c|c|c|}
\hline EKSTERNAL & $\begin{array}{l}\text { Strengths (S) / Kekuatan } \\
\text { 1. Pemberian beasiswa } \\
\text { 2. Akreditasi lembaga } \\
\text { pendidikan } \\
\text { 3. Keberadaan ekstrakurikuler } \\
\text { 4. Biaya pendaftaran } \\
\text { 5. Biaya SPP } \\
\text { 6. Sistem pembayaran } \\
\text { 7. Lokasi kampus strategis } \\
\text { 8. Lokasi kampus aman } \\
\text { nyaman } \\
\text { 9. Registrasi mudah } \\
\text { 10. Kemudahan melakukan } \\
\text { keluhan akademik } \\
\text { 11. Jenjang pendidikan dosen } \\
\text { 12. Keramahan tenaga } \\
\text { administrasi } \\
\text { 13. Kenyamanan staff kemanan } \\
\text { 14. Tampilan bangunan } \\
\text { 15. Prasarana penujang } \\
\text { 16. Kebersihan \& kenyamanan } \\
\text { ruang kelas }\end{array}$ & $\begin{array}{l}\text { Weaknesses (W) / Kelema- } \\
\text { han } \\
\text { 1. Kesesuaian mata kuliah } \\
\text { dengan kebutuhan pasar } \\
\text { tenaga kerja } \\
\text { 2. Kerja sama dengan berbagai } \\
\text { perusahaan untuk program } \\
\text { magang sebagai media } \\
\text { memperkenalkan mahasiswa } \\
\text { di dunia kerja } \\
\text { 3. Kesesuaian biaya kuliah } \\
\text { dengan fasilitas yang } \\
\text { diterima } \\
\text { 4. Promosi melalui media cetak } \\
\text { 5. Promosi melalui internet } \\
\text { 6. Promosi oleh alumni } \\
\text { 7. Promosi melalui sosialisasi } \\
\text { ke SMA } \\
\text { 8. Promosi melalui pameran } \\
\text { pendidikan } \\
\text { 9. Kemampuan mengajar } \\
\text { dosen } \\
\text { 10. Kemampuan dosen } \\
\text { memberikan motivasi } \\
\text { belajar mahasiswa } \\
\text { 11. Kerjasama dngan alumni PS } \\
\text { D-III UPW } \\
\text { 12. Kesesuaian antara teori \& } \\
\text { praktek } \\
\text { 13. Keberadaan sarana } \\
\text { perkuliahan } \\
\text { 14. Keberadaan prasarana } \\
\text { pendukung perkuliahan } \\
\end{array}$ \\
\hline $\begin{array}{l}\text { Opportunities (O) Peluang } \\
\text { 1. Perkembangan industri } \\
\text { pariwisata di Jember } \\
\text { 2. Kerjasama dengan berbagai } \\
\text { instansi dalam pemberian } \\
\text { beasiswa } \\
\text { 3. Globalisasi informasi } \\
\text { dalam menjangkau calon } \\
\text { mahasiswa yang lebih luas } \\
\text { 4. Teknologi informasi dalam } \\
\text { operasonal perkuliahan } \\
\text { 5. Daya minat pelajar } \\
\text { Kabupaten Jember bekerja } \\
\text { di bidang pariwisata } \\
\text { 6. Sumber daya alam } \\
\text { Kabupaten Jember dalam } \\
\text { mengembangkan pariwisata } \\
\text { Jember }\end{array}$ & $\begin{array}{l}\text { Strategi SO } \\
\text { 1. Peningkatan teknologi } \\
\text { informasi untuk berbagai } \\
\text { kepentingan perkuliahan di } \\
\text { PS D-III UPW } \\
\text { 2. Peningkatan daya minat } \\
\text { pelajar terhadap PS D-III } \\
\text { UPW }\end{array}$ & $\begin{array}{l}\text { Strategi WO } \\
\text { 1. Peningkatan Kerjasama } \\
\text { 2. Peningkatan promosi PS } \\
\text { D-III UPW melalui berbagai } \\
\text { media } \\
\text { 3. Peningkatan sarana dan } \\
\text { prasarana PS D-III UPW }\end{array}$ \\
\hline $\begin{array}{l}\text { Threats (T) / Ancaman } \\
\text { 1. Intensitas daya saing } \\
\text { Universitas Jember } \\
\text { dengan universitas lain di } \\
\text { Kabupaten Jember yang } \\
\text { memiliki jurusan bidang } \\
\text { pariwisata } \\
\text { 2. Peranan Pemerintah } \\
\text { Kabupaten Jember pada } \\
\text { pembangunan pariwisata } \\
\text { 3. Kebijakan Pemerintah } \\
\text { Kabupaten Jember tentang } \\
\text { agendapariwisata }\end{array}$ & $\begin{array}{l}\text { Strategi ST } \\
\text { 1. Peningkatan keunggulan PS } \\
\text { D-III UPW }\end{array}$ & $\begin{array}{l}\text { Strategi WT } \\
\text { 1. Pemantapan matakuliah } \\
\text { yg mencerminkan PS D-III } \\
\text { UPW } \\
\text { 2. Peningkatan kualitas sumber } \\
\text { daya manusia PS D-III UPW } \\
\text { 3. Menciptakan kerjasama } \\
\text { antara PS D-III UPW } \\
\text { dengan pemerintah dalam } \\
\text { pengadaan event pariwisata }\end{array}$ \\
\hline
\end{tabular}

Sumber : Data Diolah, 2015 
Tabel 3.4 Hasil Analisis QSPM PS D-III UPW

\begin{tabular}{ccccccc}
\hline \multirow{2}{*}{ Strategi } & \multicolumn{3}{c}{ Strategi TAS } & \multirow{2}{*}{ Jumlah } & Rata-rata & Peringkat \\
\cline { 2 - 4 } & Informan 1 & Informan 2 & Informan 3 & & & \\
\hline SO 1 & 18.625 & 18.245 & 17.537 & 54.407 & 18.135 & 8 \\
SO 2 & 21.225 & 20.881 & 20.205 & 62.311 & 20.770 & 2 \\
WO 1 & 20.774 & 20.249 & 19.98 & 61.003 & 20.334 & 3 \\
WO 2 & 21.996 & 21.136 & 21.614 & 64.746 & 21.582 & 1 \\
WO 3 & 17.912 & 17.057 & 17.348 & 52.317 & 17.439 & 9 \\
ST 1 & 18.374 & 18.031 & 21.687 & 58.092 & 19.364 & 5 \\
WT 1 & 18.801 & 18.467 & 18.404 & 55.672 & 18.557 & 7 \\
WT 2 & 19.739 & 20.55 & 19.211 & 59.5 & 19.833 & 4 \\
WT 3 & 19.262 & 18.707 & 18.573 & 56.542 & 18.847 & 6 \\
\hline
\end{tabular}

Sumber : Data Diolah, 2015

\section{dalam kegiatan pariwisata (18.847)}

7. Pemantapan mata kuliah yang mencerminkan PS D-III UPW (18.557)

8. Peningkatan teknologi informasi untuk berbagai kepentingan perkuliahan di PS D-III UPW (18.135)

9. Peningkatan sarana dan prasarana PS D-III UPW (17.439)

Hasil QSPM menunjukkan bahwa peningkatan promosi melalui berbagai media seperti media cetak, internet, sosialisasi dan promosi oleh alumni merupakan strategi yang perlu di prioritaskan agar PS D-III UPW semakin dikenal masyarakat luas dan menjangkau calon mahasiswa lebih banyak lagi. Selain itu, melakukan berbagai kegiatan dalam rangka meningkatkan daya minat pelajar untuk melanjutkan pendidikan di PS D-III UPW seperti mengundang pelajar dalam pentas seni, seminar atau workshop pariwisata, Selanjutnya peningkatan kerjasama dengan berbagai lembaga baik negeri maupun swasta dalam berbagai bidang, kerjasama beasiswa, kunjungan ke perusahaan, dan tempat praktek kerja mahasiswa, serta pencarian dana sponsor kegiatan mahasiswa.

\section{Penutup}

\subsection{Simpulan}

Hasil yang diperoleh berdasarkan identifikasi faktor strategis internal melalui faktor kekuatan, yaitu pemberian beasiswa, akreditasi lembaga pendidikan, keberadaan ekstrakurikuler, biaya pendaftaran, biaya SPP, sistem pembayaran, lokasi kampus strategis, lokasi kampus aman nyaman, registrasi mudah, kemudahan melakukan keluhan akademik, jenjang pendidikan dosen, keramahan tenaga administrasi, kinerja staf keamanan, tampilan bangunan, prasarana penunjang, kebersihan dan kenyamanan ruang kelas.

Faktor kelemahan yaitu kesesuaian mata kuliah, kerja sama dengan berbagai perusahaan, kesesuaian biaya kuliah dengan fasilitas yang 
dihasilkan melalui analisis QSPM, yaitu peningkatan promosi yang dinilai sebagai strategi yang perlu segera diterapkan.

\subsection{Saran}

Berdasarkan analisis dan uraian terhadap lingkungan strategis internal dan eksternal PS D-III UPW di Universitas Jember, kepada pihak universitas yaitu diharapkan dapat mengimplementasikan strategi-strategi yang telah dirumuskan pada artikel ini. Strategi tersebut adalah peningkatan teknologi informasi, peningkatan daya minat pelajar, peningkatan kerja sama, peningkatan promosi, peningkatan sarana prasarana pendidikan, peningkatan keunggulan program studi, pemantapan matakuliah, peningkatan kualitas SDM, dan pelibatan mahasiswa diberbagai event pariwisata yang diselenggarakan pemerintah Kabupaten Jember. Untuk pemerintah adalah lebih serius dalam membangun pariwisata Jember, memperbaiki aksessibilitas dan sarana prasarana pariwisata serta lebih meningkatkan pengadaan event-event pariwisata sehingga mahasiswa pariwisata juga dapat mengaplikasikan ilmu pariwisatanya dengan turut berperan serta dalam event pariwisata yang diadakan pemerintah.

\section{Ucapan Terima Kasih}

Artikel ini merupakan ringkasan tesis yang dibuat dengan saran dari pembimbing dan pihak lainnya. Oleh karena itu pada kesempatan ini, penulis hendak menyampaikan terima kasih sebesar-besarnya kepada Prof. Dr. I Nyoman Darma Putra, M.Litt selaku pembimbing I yang dengan kesabaran memberikan bimbingan, masukan, koreksi dan saran untuk kesempurnaan tesis. Terimakasih sebesar-besarnya juga disampaikan kepada Dr. I Nyoman Madiun,M.Sc selaku pembimbing II yang telah memberikan bimbingan, petunjuk, koreksi maupun saran mengenai isi dan teknis penulisan selama penyusunan tesis. Ucapan terima kasih disampaikan juga kepada para penguji yaitu Prof. Dr. Made Budiarsa, M.A., Dr. Ir. Syamsul Alam Paturisi, MSP., dan Dr. I Nyoman Sudiarta, SE., M.Par. yang telah banyak memberikan masukan, kritik dan saran serta koreksi demi kesempurnaan penulisan tesis.

\section{Daftar Pustaka}

Evans, Nigel., David Champbell, dan George Stonehouse. 2003. Strategic Management for Travel and Tourism. Oxford: Butterworth-Heinemann

Davis, B \& L. Ellison. 1997. Strategic Marketing for School : How Integrate Marketing and Strategic Development for An Effective School. London: Picman Publishing.

Irwansyah. 2011. "Pengembangan Sumber Daya Manusia Indonesia di Bidang Pariwisata”. (Skripsi). Semarang: Sekolah Tinggi ilmu ekonomi Pariwisata Indonesia. 
Ismayanti. 2010. Pengantar Pariwisata. Jakarta: PT Gramedia Widisarana Indonesia.

Morrison, Alastair M. 2002. Hospitality and Travel Marketing. USA: Delmar Thomson Learning.

\section{Profil Penulis}

Margaretta Andini Nugroho, SST. Par. adalah alumnus Kajian Magister Pariwisata Universitas Udayana Denpasar. Ia menyelesaikan Program Studi DIV Pariwisata pada tahun 2012 di Universitas Udayana. Saat ini bekerja sebagai Dosen di Prodi DIII Usaha Perjalanan Wisata Universitas Jember.

I Nyoman Darma Putra adalah guru besar Fakultas Ilmu Budaya dan Ketua Program Studi Magister Kajian Pariwisata, Universitas Udayana. Darma menulis beberapa artikel di jurnal internasional dan beberap buku biografi tokoh pariwisata Bali, serta menyunting beberapa buku, termasuk Pariwisata Berbasis Masyarakat Model Bali (2015) dan bersama Siobhan Campbell mengedit buku Recent Developments in Bali Tourism: Culture, Heritage, and Landscape in an Open Fortress (2015). Bersama Diah Sastri Pitanatri, Darma menulis buku Wisata Kuliner, Atribut Baru Destinasi Ubud (2016). Email: idarmaputra@yahoo.com 